\title{
EFEKTIVITAS PELAKSANAAN PRAKTEK PEMBANGUNAN KESEHATAN MASYARAKAT SEKOLAH (PKMS) TAHUN AKADEMIK 2009/2010 TERHADAP PENINGKATAN SKILL MAHASISWA D3 KEPERAWATAN
}

\author{
The Effectiveness Of Community Health Practice (Pkms) To The Skill Increasing Of \\ Diploma Nursing Student Muhammadiyah University Of Malang 2009
}

\author{
Sri Sunaring Ika Wardojo
}

\author{
Program Studi Ilmu Keperawatan Fakultas Ilmu Kesehatan Universitas Muhammadiyah Malang \\ Jl. Bendungan Sutami 188A Malang 65145 \\ e-mail: ikawardojo@yahoo.com
}

\begin{abstract}
ABSTRAK
Kegiatan praktek pembangunan kesehatan masyarakat sekolah (PKMS) yang diikuti oleh seluruh mahasiswa program Diploma (D3) Keperawatan semester VI Fakultas Ilmu Kesehatan Universitas Muhammadiyah Malang bertujuan agar mahasiswa memiliki pengalaman untuk memberikan pelayanan keperawatan kepada keluarga, lansia dan masyarakat sekolah dengan masalah kesehatan baik yang aktual, resiko maupun potensial dengan menggunakan pendekatan asuhan keperawatan keluarga, gerontik, dan komunitas dengan berbagai agregat (berdasarkan setting tempat, penyakit, usia) dengan pendekatan komunitas sebagai mitra (community as partner). Penelitian ini bertujuan untuk mengetahui tentang efektivitas pelaksanaan program praktek pembangunan kesehatan masyarakat sekolah (PKMS) terhadap peningkatan skillmahasiswa. Penelitian ini termasuk dalam cross sectional study dengan menggunakan desain deskriptif komparatif. Pengambilan sample dilakukan dengan teknik accidental sampling. Populasi dalam penelitian ini adalah mahasiswa D3 Keperawatan FIKES UMM semester VI, sedangkan sample dalam penelitian ini adalah mahasiswa D3 Keperawatan yang mengikuti program praktek pembangunan kesehatan masyarakat sekolah (PKMS) baik sebanyak 69 orang. Penelitian dilaksanakan sejak bulan Desember 2009-Mei 2010. Instrumen yang digunakan dalam penelitan ini adalah menggunakan kuesioner soal pre test dan post test yang masing-masing berisi 10 item pertanyaan yang sama. Untuk mengetahui efektivitas pelaksanaan program ini terhadap peningkatan pengatahuan mahasiswa dapat dibandingkan skor pada pre test dengan post test kemudian dianalisis menggunakan uji $\mathrm{t}$ berpasangan (paired t test). Hasil uji statistik didapatkan nilai $\mathrm{p}=$ 0,00 ( $<$ á), sehingga dapat diambil kesimpulan bahwa terdapat perbedaan yang signifikan antara nilai pretes dengan posttest. Dengan kata lain, pelaksanaan program ini efektif terhadap peningkatan skill mahasiswa D3 Keperawatan dalam bidang keperawatan komunitas, keperawatan keluarga dan keperawatan gerontik.
\end{abstract}

Kata kunci: efektivitas, PKMS, skill, mahasiswa D3 keperawatan

\section{ABSTRACT}

This community practical study, which was attended by all of the 3hd grade Nursing Diploma's students of University of Muhammadiyah Malang, aims to enable the students having experience to provide family health care with actual and potential health problem using the approach of family nursing careplan, provide nursing services to elderly family members who have health problems due to aging (degenerative process) using the approach of gerontology nursing careplan, and conduct community nursing careplan with a variety of aggregate (based on spot settings, disease, age) with community as a partner. This study aimed to find out about the effectivity of community practical study related with increasing of the student's knowledge and skills. This is a cross sectional study using a comparative descriptive design. Sampling is done by accidental sampling technique. The population were the Nursing Diploma's students of University of Muhammadiyah Malang, while the samples were 69 students. Research conducted since December 2009-May 2010. The instrument used in this research is pretest and post test quesstionnaire. To examine the effectiveness of this program related with increasing of the students's knowledge, can be analyzed using paired t test (paired t test). Results of statistical test $p$ value $=0.00(p$ $<a)$, so it can be concluded that there are significant differences between the pretest and posttest. In other 
words, the implementation of this program is quite effective against student skill development in the field of community nursing, family nursing and gerontology nursing.

Keywords: effectivity, community practical study, skill, student

\section{LATAR BELAKANG}

Kegiatan praktek pembangunan kesehatan masyarakat sekolah (PKMS) merupakan bentuk pembelajaran bagi mahasiswa untuk menerapkan ilmu keperawatan komunitas secara komprehensif. Ilmu komunitas yang diaplikasikan dalam bentuk praktek lapangan meliputi: asuhan keperawatan keluarga, asuhan keperawatan gerontik, dan asuhan keperawatan komunitas. Kegiatan ini juga mencerminkan kegiatan pengabdian masyarakat sebagai salah satu wujud dari pelaksanaan tri dharma perguruan tinggi. Kegiatan praktek lapangan ini menggunakan beberapa pendekatan yaitu pendekatan proses keperawatan (pengkajian, diagnosa keperawatan, perencanaan, pelaksanaan dan evaluasi), pendekatan statistik dan epidemiologi, serta pengembangan dan pengorganisasian masyarakat (Tim Komunitas FIKES UMM, 2009).

Program praktek lapangan komunitas atau lebih sering disebut dengan PKMS (praktek keperawatan masyarakat sekolah) ini diikuti oleh seluruh mahasiswa program Diploma (D3) Keperawatan semester VI Fakultas Ilmu Kesehatan Universitas Muhammadiyah Malang. Kegiatan ini telah dilaksanakan dalam tiga periode berturut-turut sejak tahun akademik 2007/2008. Untuk periode dua tahun pertama pelaksanaan praktek mahasiswa, yaitu pada tahun akademik 2008/2009 dan tahun akademik 2008/2009, selain berfokus pada masalah kesehatan keluarga dan lansia, juga menitikberatkan pada masalah kesehatan komunitas masyarakat industri dan masyarakat sekolah. Sedangkan pada tahun ketiga (tahun akademik 2009/2010), kegiatan praktek ini hanya memfokuskan diri pada komunitas masyarakat sekolah, selain masalah kesehatan lansia dan keluarga. Hal ini dikarenakan dengan lebih spesifiknya lingkup agregat komunitas pada lahan praktek (komunitas masyarakat sekolah tanpa komunitas masyarakat industri) dan dengan terbatasnya waktu praktek untuk setiap mahasiswa (1 bulan), diharapkan pelaksanaan praktek mahasiwa lebih efektif dan efisien sehingga dapat memberikan skill yang lebih pada mahasiswa dibandingkan dengan dua periode sebelumnya. Untuk periode ketiga (tahun akademik 2009/2010), kegiatan praktek pembangunan kesehatan masyarakat sekolah (PKMS) ini diadakan dalam 6 (enam) gelombang sejak bulan Desember 2009 sampai dengan Mei 2010. Masing-masing gelombang diikuti oleh 14 mahasiswa, dengan lahan praktek yang berbeda-beda. Lahan praktek yang digunakan dalam program praktek pembangunan kesehatan masyarakat sekolah (PKMS) tahun akademik 2009/2010 antara lain adalah SMK Negeri 1 Malang, TK Negeri Internasional, SMA Negeri 6 Malang, SLTP Negeri 1 Malang, SMA Negeri 9 Malang, SD Negeri Klojen Malang, Puskesmas Janti, Puskesmas Arjowinangun, Puskesmas Kedungkandang, Puskesmas Arjuno, Puskesmas Mojolangu, dan Puskesmas Rampal Celaket.

Pelaksanakan kegiatan praktek lapangan keperawatan komunitas ini melibatkan seluruh potensi yang ada di masyarakat dan bekerjasama lintas sektoral dalam melaksanakan upaya-upaya kesehatan dasar untuk memenuhi kebutuhan kesehatan masyarakat melalui program-program yang dilaksanakan secara bersama-sama. Kerjasama lintas sektoral dilakukan dengan beberapa instansi terkait seperti dinas kesehatan, puskesmas, dinas pendidikan nasional, tim pembina UKS, dan lain-lain. Kegiatan praktek pembangunan kesehatan masyarakat sekolah (PKMS) memiliki target 
populasi sesuai dengan kompetensi yang keilmuan yang mendasari yaitu keperawatan keluarga, gerontik, dan komunitas. Target populasi untuk keperawatan keluarga adalah keluarga dengan berbagai masalah kesehatan dengan kriteria aktual, resiko, dan potensial. Target populasi gerontik adalah keluarga yang memiliki anggota keluarga lanjut usia (lansia) dengan berbagai masalah kesehatan terkait dengan penurunan kemampuan (proses degeneratif). Target populasi komunitas adalah sekelompok (agregat) yang didasarkan pada setting lokasi masyarakat sekolah.

Tujuan pelaksanaan dari program praktek ini adalah supaya mahasiswa mampu memberikan pelayanan keperawatan kepada keluarga dengan masalah kesehatan baik yang aktual, resiko maupun potensial dengan menggunakan pendekatan asuhan keperawatan keluarga, memberikan pelayanan keperawatan kepada keluarga yang memiliki anggota keluarga dalam lanjut usia (lansia) yang mengalami masalah kesehatan akibat proses penuaan (proses degeneratif) menggunakan pendekatan asuhan keperawatan pada gerontik serta melakukan asuhan keperawatan komunitas dengan berbagai agregat (berdasarkan setting tempat, penyakit, usia) dengan pendekatan komunitas sebagai mitra (community as partner). Berdasarkan penelitian Yoyok Bekti (2009), terdapat peningkatan yang signifikan terhadap skill mahasiswa karena kegiatan praktek mahasiswa komunitas tahun akademik 2008/ 2009, tetapi dengan setting masyarakat industri, sedangkan penelitian yang berkaitan dengan praktek mahasiswa komunita dengan setting masyarkat sekolah belum pernah dilakukan, sehingga peneliti tertarik untuk mengadakan penelitian tentang efektivitas pelaksanaan program praktek pembangunan kesehatan masyarakat sekolah (PKMS) tahun akademik 2009/2010 terhadap peningkatan skill mahasiswa program D3 Keperawatan Fakultas Ilmu Kesehatan Universitas Muhammadiyah Malang.

\section{METODE}

Penelitian cross sectional study dengan menggunakan desain deskriptif komparatif. (Sugiyono, 2002) Penelitian bertujuan untuk membandingkan tingkat skill mahasiswa terhadap kegiatan ini, sebelum dan sesudah dilakukan kegiatan praktek pembangunan kesehatan masyarakat sekolah (PKMS). Pengambilan sampel dilakukan dengan teknik accidental sampling, hal ini disebabkan terdapat beberapa mahasiswa yang tidak mengikuti program ini tidak secara lengkap dari awal kegiatan sampai akhir kegiatan. Populasi dalam penelitian ini adalah mahasiswa D3 Keperawatan FIKES UMM semester VI, sedangkan sample penelitian ini adalah mahasiswa D3 Keperawatan yang mengikuti program PKMS baik dari proses pre test sampai dengan post test dengan lengkap sebanyak 69 orang. Penelitian dilaksanakan sejak bulan Desember 2009 sampai dengan Mei 2010. Instrumen yang digunakan dalam penelitan ini adalah menggunakan kuesioner soal pre test dan post test yang masing-masing berisi 10 item pertanyaan. Pertanyaan tersebut dikembangkan berdasarkan proses identifikasi, analisis permasalahan implementasi program sampai dengan evaluasi pelaksanaan kegiatan. Penelitian ini dilakukan dengan memberikan soal pre test pada mahasiswa tiap-tiap gelombang sebelum mengawali kegiatan praktek pembangunan kesehatan masyarakat sekolah (PKMS) dan pemberian soal post test setelah mahasiswa menyelesaikan program praktek. Variabel independen adalah pelaksanaan program PKMS, sedangkan variabel dependen adalah peningkatan skill mahasiswa. Untuk mengetahui efektivitas pelaksanaan program ini terhadap peningkatan skill mahasiswa dapat dibandingkan skor pada pre test dengan post test kemudian dianalisis menggunakan uji t berpasangan (paired $t$ test). 
HASIL DAN PEMBAHASAN

Tabel 1. Distribusi karakteristik responden berdasarkan usia dan jenis kelamin

\begin{tabular}{ccccc}
\hline No & Usia (tahun) & Jumlah (n) & Prosentase (\%) \\
\hline 1. & 21 & & 22 & 31 \\
2. & 22 & & 28 & 41 \\
3. & 23 & & 19 & 28 \\
\hline No & Jenis Kelamin & Jumlah (n) & Prosentase (\%) \\
\hline 1. & Perempuan & 49 & 71 \\
2. & Laki-Laki & 20 & 29 \\
\hline \multicolumn{2}{r}{} & Total & $\mathbf{6 9}$ & $\mathbf{1 0 0}$
\end{tabular}

Dari table di atas didapatkan hasil penelitian, bahwa mayoritas responden berusia 22 tahun sebanyak 28 orang $(41 \%)$, sedangkan sebanyak 22 mahasiswa (31\%) berusia 21 tahun. Sisanya sebanyak 19 orang (28\%) mahasiswa berusia 23 tahun.

Selain itu, diketahui bahwa dari 69 orang responden, yang berjenis kelamin perempuan sebanyak 49 orang $(71 \%)$, sedangkan sisanya adalah laki-laki sebesar 20 orang ( $29 \%$ ).

Tabel 2. Distribusi peningakatan skill mahasiswa D3 Keperawatan FIKES UMM terhadap praktek PKMS berdasarkan hasil pre test dan post test tahun akademik 2009/2010

\begin{tabular}{|c|c|c|c|c|c|c|c|}
\hline & & Mean & $\mathbf{N}$ & $\begin{array}{l}\text { Std. } \\
\text { Deviation }\end{array}$ & $\begin{array}{l}\text { Std. } \\
\text { Mean }\end{array}$ & Error & $P$ value \\
\hline Pair 1 & Pre Test & 71,01 & 69 & 1,519 & 12,619 & & \multirow{2}{*}{0,00} \\
\hline & Post Test & 77,54 & 69 & 1,296 & 10,766 & & \\
\hline
\end{tabular}

Dari tabel 2 diketahui bahwa rata-rata nilai pre test dari 69 mahasiswa adalah 71,01 dengan standar deviasi 12,619. Sedangkan dari nilai post test diketahui bahwa reratanya adalah 77,54 dengan standar deviasinya 10,766. Selain itu, hasil uji statistik didapatkan nilai $\mathrm{p}=0,00(\mathrm{p}<$ á), sehingga dapat diambil kesimpulan bahwa terjadi peningkatan skill pada mahasiswa dari kegiatan PKMS ini. Hal tersebut ditunjukkan dengan rerata nilai post test mahasiswa lebih tinggi daripada rerata nilai pre test.

Hal tersebut menunjukkan bahwa pelaksanaan kegiatan praktek ini cukup efektif untuk meningkatkan skill mahasiswa tentang asuhan keperawatan komunitas, asuhan keperawatan keluarga dan asuhan keperawatan gerontik. Sehingga diharapkan pelaksanaan kegiatan ini dapat terus

\section{Efektivitas Pelaksanaan Praktek Pembangunan Masyarakat Sekolah (PKMS) terhadap Peningkatan Skill Mahasiswa}

Hasil analisis menggunakan paired $t$ test diketahui sebagai berikut:

\section{Karakteristik Responden Berdasarkan Usia}

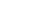


dilakukan oleh Yoyok Bekti (2009), yang menyebutkan bahwa terdapat peningkatan yang signifikan terhadap skill mahasiswa keperawatan akibat dari kegiatan praktek komunitas dengan setting masyarakat industri.

Hal tersebut disebabkan dalam pelaksanaan praktek PKMS selama satu bulan lama, mahasiswa dituntut untuk memberikan pelayanan keperawatan kepada keluarga maupun lansia dengan masalah kesehatan baik yang aktual, resiko maupun potensial dengan menggunakan pendekatan asuhan keperawatan keluarga dan asuhan keperawatan gerontik dan diwajibkan untuk membuat laporan secara mandiri. Serta mahasiswa secara berkelompok (14 orang) diberi tanggung jawab untuk melakukan asuhan keperawatan komunitas dengan agregat kelompok masyarakat sekolah dengan pendekatan komunitas sebagai mitra (community as partner) melalui rangkaian kegiatan pengkajian, intervensi, implementasi program dan evaluasi program.

\section{KESIMPULAN DAN SARAN}

Berdasarkan hasil penelitian, dapat disimpulkan bahwa terjadi peningkatan skill mahasiswa dari kegiatan PKMS tahun akademik 2009/2010 ini. Hal tersebut ditunjukkan dengan rerata nilai post test mahasiswa lebih tinggi daripada rerata nilai pre test.

Hal tersebut menunjukkan bahwa pelaksanaan kegiatan praktek PKMS ini efektif untuk meningkatkan skill mahasiswa tentang asuhan keperawatan komunitas, asuhan keperawatan keluarga dan asuhan keperawatan gerontik.

Saran yang dapat diberikan bagi pembimbing institusi adalah dapat memberikan pengarahan kepada mahasiswa agar setiap mahasiswa memiliki motivasi dan persepsi yang baik terhadap kompetensi skill yang dicapai dalam praktek asuhan keperawatan komunitas, gerontik dan keluarga. Hasil penelitian ini dapat digunakan sebagai acuan untuk melakukan penelitian lanjutan dengan sampel yang lebih besar dan mengangkat masalah yang berkaitan dengan profesi perawat yang belum dibahas dalam penelitian ini serta masih perlu diadakan uji coba atau validitas dan realibilitas terhadap alat ukur.

\section{DAFTAR PUSTAKA}

Anderson \& Mc Farlane. 2000. Community as Partner: Theory and Practice in Nursing. $3^{\text {th }}$ Edition. Philadelphia: Lippincott Williams and Wilkins.

Bekti, Y. 2009. Efektivitas Pembelajaran pada Stase Departemen Keperawatan Komunitas mahasiswa Profesi Program D3 Keperawatan Tahun Akademik 2008/2009.

Effendi, N. 1998. Dasar-Dasar Keperawatan Kesehatan Masyarakat. Jakarta: EGC.

Kuzma \& Bohnenblust. 2005. Basic Statistics for the Health Science. New York: McGraw-Hill.

McMurray, A. 2003. Community Health and Wellness a Socioecological Approach. The Mosby: St Louis.

Stanhope, M., Lancaster, J. 2004. Community and Public Health Nursing. The Mosby Year Book: St Louis.

Sugiyono. 2002. Statistika Untuk Penelitian. Bandung: CV. Alfabeta.

Tim Departemen Komunitas. 2009. Panduan Praktik Profesi Departemen Komunitas Bagi Mahasiswa D3 Keperawatan. Malang: FIKES UMM. 